Article

\title{
A Design of the Compression Chamber and Optimization of the Sealing of a Novel Rotary Internal Combustion Engine Using CFD
}

\author{
Savvas Savvakis*(D), Dimitrios Mertzis $\mathbb{D}^{\text {, }}$, Elias Nassiopoulos and Zissis Samaras \\ Department of Mechanical Engineering, Aristotle University of Thessaloniki, 54124 Thessaloniki, Greece; \\ jimmer@auth.gr (D.M.); i.nassiopoulos@gmail.com (E.N.); zisis@auth.gr (Z.S.) \\ * Correspondence: savvas@theSARMproject.com
}

Received: 29 March 2020; Accepted: 1 May 2020; Published: 9 May 2020

check for updates

\begin{abstract}
The current paper investigates two particular features of a novel rotary split engine. This internal combustion engine incorporates a number of positive advantages in comparison to conventional reciprocating piston engines. As a split engine, it is characterized by a significant difference between the expansion and compression ratios, the former being higher. The processes are decoupled and take place simultaneously, in different chambers and on the different sides of the rotating pistons. Initially, a brief description of the engine's structure and operating principle is provided. Next, the configuration of the compression chamber and the sealing system are examined. The numerical study is conducted using CFD simulation models, with the relevant assumptions and boundary conditions. Two parameters of the compression chamber were studied, the intake port design (initial and optimized) and the sealing system size (short and long). The best option was found to be the combination of the optimized intake port design with the short seal, in order to keep the compression chamber as close as possible to the engine shaft. A more detailed study of the sealing system included different labyrinth geometries. It was found that the stepped labyrinth achieves the highest sealing efficiency.
\end{abstract}

Keywords: SARM; rotary engine; compression chamber; combustion chamber; sealing; CFD

\section{Introduction}

Aiming at the mitigation of the Greenhouse Effect, stringent $\mathrm{CO}_{2}$ emission regulations and targets have been set, for passenger cars and light commercial vehicles (e.g., in the European Commission [1] and in the US [2]), as well as heavy-duty vehicles [3]. Such targets pose strong challenges to the automotive sector.

Various pathways can be followed in order to address these challenges. Although electrification is probably the most widely applied solution, it is only the battery electric vehicle (BEV, charged by the grid, or FCEV) that is completely independent from an "onboard" thermal engine and becomes completely independent from thermal energy only in the case that grid electricity (or hydrogen for FCEV) is produced by renewable sources (sun, wind, water, etc.). In addition, there is a number of key factors (such as battery cost, recharging infrastructure network, and $\mathrm{CO}_{2}$ car standards) that greatly influence BEV's market penetration [4]. On the other hand, hybrid vehicles (HEV, PHEV, range extender) are still equipped with a thermal engine.

Another pathway is fuel decarbonisation. In this case, alternative fuels with lower carbon content can be used (e.g., natural gas, consisting mainly of methane), while also (green) e-fuels are developed, which are synthetic fuels produced by the extensive use of renewable energy, thus reducing $\mathrm{CO}_{2}$ emissions of the complete fuel life cycle [5]. Independently, however, of the fuel production process 
and properties, this is used in a thermal engine, in a variety of applications ranging from road transport to shipping [6].

It is clear from the above that the internal combustion engine (ICE) still plays, and will continue to play, an important role in transportation systems. Thus, it is of great importance to make the internal combustion engine as efficient as possible, always keeping the right balance between fuel economy and pollutant emissions. To that aim, various roadmaps have been developed around the globe towards the development of highly efficient thermal engines, with the efficiency target reaching $50 \%$ in passenger car applications [7] and 55\% in heavy-duty applications (US Super Truck program [8,9]), while currently the peak performance in passenger cars is in the order of $40 \%$ [7].

As a result, considerable resources are invested in developing fuel economy and boosting technologies, optimising engine combustion strategies and thermal management, using alternative operating cycles like the Atkinson, inventing new concepts and technologies, developing controllers and others [10]. However, most engines operate at less than half of the Carnot cycle theoretical efficiency limit [11]. The main development activities focus on the reciprocating piston ICE, which, however, presents a number of disadvantages in terms of engine dynamics, due to the necessary conversion of the reciprocating to rotational motion. The latter results in bigger and heavier constructions, suffering from oscillations and producing only part of the theoretically available power and torque.

On the other hand, there is no intense research on rotary engines, resulting in only one commercially available engine for passenger cars, the (four stroke) Wankel engine, also used in other applications (e.g., aviation, motorsport) [12], while its two-stroke version is also examined in combination with supercharging aiming at higher power density [13]. The main drawbacks of this engine are the combustion chamber shape (high surface to volume ratio at ignition) and the leakage of the working medium between the adjacent chambers (blow-by effect) [14]. In order to overcome the disadvantages of the existing ICEs, various alternative concepts have been developed, such as the Revetec engine [15], the Scuderi Split Cycle (SSC) [16], the Duke engine [17] and others. An overview of such alternative concepts can be found in [18].

In the current work, a novel rotary ICE is presented, describing its novel design and operating principle, targeting higher thermal efficiency. The configuration of this engine, called the Savvakis Rotary Motor (SARM), aims at eliminating the drawbacks of the existing ICEs. Its operation is based on the Atkinson cycle, allowing for improved performance. The engine is concentric and the processes are realized in separate chambers with individual pistons.

The objective of the present work is to investigate in more details two particular features of this novel engine, namely the compression chamber design and the sealing system. To that aim, mathematical models are setup in commercial CFD software (Computational Fluid Dynamics), commonly used in such investigations [19], combined with the relevant assumptions and boundary conditions. After the description of the structure of the engine and its operating principle, the computational tools are presented, including the meshes and the parameters examined. The results section highlights the advantages of the different configurations, concluding with the optimum solution.

\section{Materials and Methods}

\subsection{Engine Description}

This section provides a brief description of the technical features and its operation. The detailed technical description of the engine and its operating principle, together with the justification of the selection of geometrical features, is shown in [20]. Figure 1 presents the layout of the engine, where its main technical characteristics are shown. The advantages of the SARM engine are presented in Section 2.1.4. 


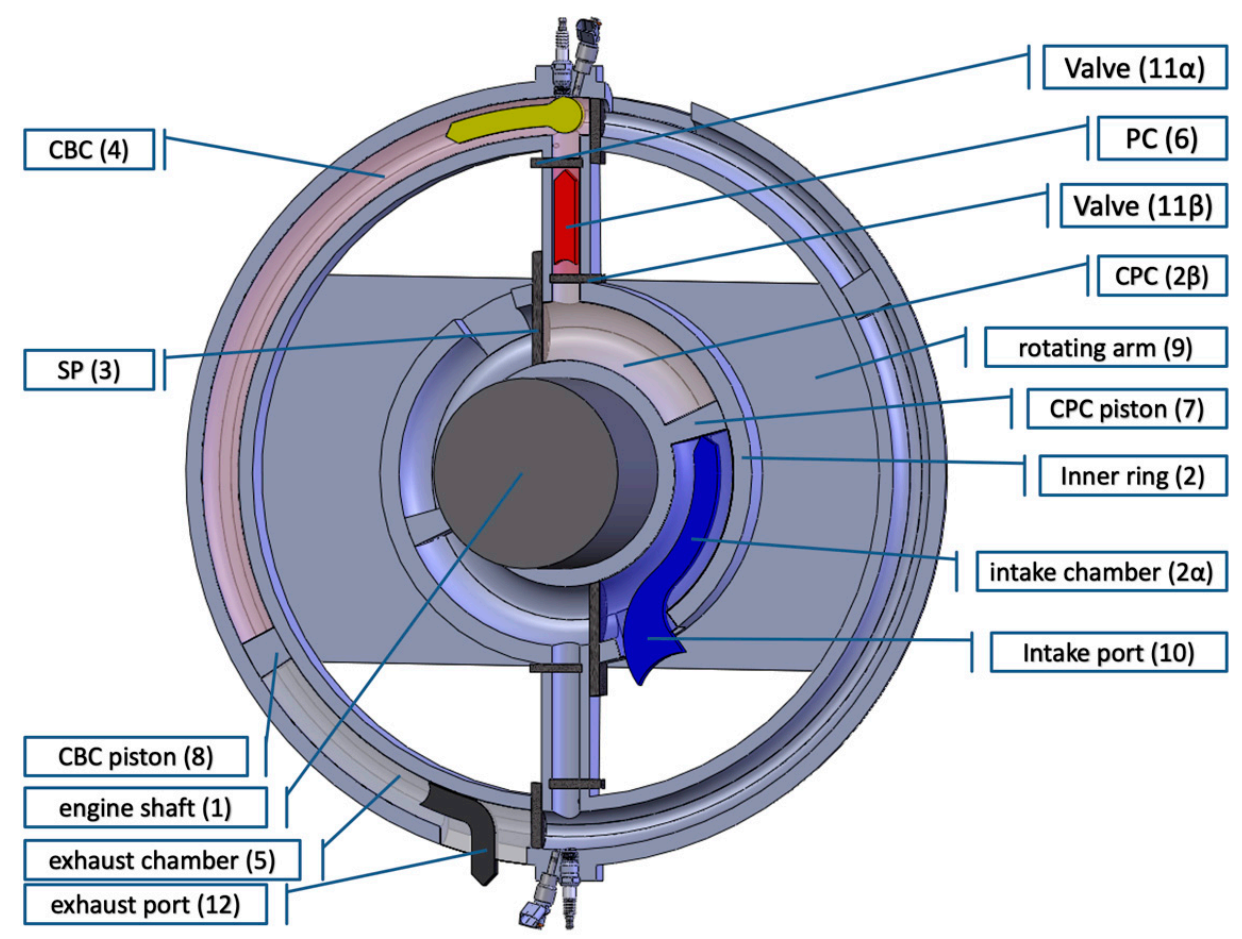

Figure 1. Savvakis Rotary Motor (SARM) engine layout.

\subsubsection{Engine Components}

With reference to Figure 1:

- The engine consists of two concentric toroidal rings of significantly different diameter. At the common center of the two rings the engine shaft (1) (power output) is located.

- The inner ring (2) forms the intake $(2 \alpha)$ and compression $(2 \beta)$ chamber $(\mathrm{CPC}=$ ComPression Chamber), while the outer one is the combustion ( $\mathrm{CBC}=$ ComBustionChamber) (4) and exhaust (5) chamber.

- The CPC and the CBC communicate through an intermediate chamber, which is called the Pressure Chamber (PC) (6).

- Gas exchange between the chambers (from the CPC to the PC and then to CBC) is achieved with the use of sliding ports and valves.

- Within each chamber, a pair of symmetrically located pistons rotates; two pistons in the CPC (7) and two pistons in the CBC (8).

- A rotating moving arm (or disc) (9) interconnects the CBC pistons, the CPC pistons and the shaft of the engine. All the moving parts of the engine perform rotating motion.

- Two additional major components of the engine are the fuel injector and the spark plug. The former can be placed either in the PC or the CBC, depending on the fuel injection strategy, while the latter is placed exclusively in the CBC.

- Additional peripheral components include the fuel supply lines, the electric/electronic components for operation and control, engine mounts, etc. Although such components are necessary for the operation and control, they are not related with the basic operating concept of the engine. Therefore, they are not described further here.

\subsubsection{Operating Concept}

From a thermodynamic point of view, the operating cycle of the SARM engine is based on the Atkinson cycle, which can theoretically reach up to $20 \%$ higher efficiency than the Otto cycle [21]. The major characteristic of an engine running on the Atkinson cycle is that the expansion ratio is 
higher than the compression ratio. This thermodynamic cycle is already applied in reciprocating piston engines; Toyota Prius has an effective compression ratio (CR) of 8:1 and an expansion ratio (ER) of about 13:1. After testing, Toyota concluded that the engine running on the Atkinson cycle can be $12 \%-14 \%$ more efficient than the corresponding engine running on the Otto cycle [22].

Compared to conventional reciprocating engines, where all processes take place within the engine cylinder (otherwise called the combustion chamber), but during different strokes, in this engine, all processes occur simultaneously, but in separate chambers. These types of engines are called split engines. On the other hand, all chambers, the piston's rotation and the shaft are located around the same axis, and from this point of view, it could be said that the SARM engine presents some similarities with gas turbines. Both are concentric internal combustion split engines. The presence of the pressure chamber between the compression and the combustion chambers allows for the independent optimization of each thermodynamic process (intake, compression, combustion, expansion). Decoupling the processes and the volumes where they take place offers great flexibility, e.g., on the shape and the material of each chamber, or even on the surface treatment of each chamber.

From the dynamics point of view, the SARM engine also presents some particular features. Compared to conventional reciprocating engines, the SARM engine eliminates any reciprocating motion in all directions, thus limiting oscillations and confining vibrations, mechanical losses and additional inertial forces, which increase the thickness and weight of an engine's component. Furthermore, the concentric operation of the SARM engine avoids the additional inertial forces developed by eccentricity in other rotary engines, permitting also higher piston speeds that increase the power density. Finally, the symmetric location of pistons balances the engine, neutralizing oscillations due to centrifugal and inertial forces, while in conventional reciprocating engines a system of counterweights is usually needed to balance the crankshaft. The generated symmetry of the SARM engine eliminates the mechanical vibrations and diminishes the sound effects.

\subsubsection{Phases of Operation}

The SARM engine phases of operation are depicted in Figure 2, but there is also a video that describes them which can be seen in the Supplementary Materials.

- The CPC piston (7) rotates with a speed of 100 to $12,000 \mathrm{rpm}$ inside the inner ring (2) which has a toroidal shape.

- The piston (7) and the sliding port (SP) (3) divide the inner ring (2) into two chambers; the intake chamber $(2 \alpha)$ and the compression chamber $(2 \beta)$.

- The back side of the piston (7) drags atmospheric air through the intake port (10) into the intake chamber $(2 \alpha)$, while the front side of the piston compresses the trapped air between the piston and the SP inside the compression chamber $(2 \beta)$.

- The SP (3) remains closed during the whole compression process. When the piston reaches the closed SP (3), the latter opens letting the piston to pass and then closes again.

- Valves (11 $\alpha$ and $11 \beta$ ) open 15 degrees before the SP (3) opening and the compressed air is delivered into the combustion chamber (CBC) (4) through the pressure chamber (PC) (6).

- The air transfer process is terminating with the closing of valve $(11 \beta)$. The combustion chamber (4) is now delimited by the closed expansion sliding port, the closed valve (11ß), the toroidal shell and the CBC piston (8).

- Inside the combustion chamber, the processes of fuel injection and mixing with the air take place. Combustion is initiated by a spark plug initiates the combustion process.

- The following expansion of the burning mixture exercises a force on the CBC piston (9) producing work and, through the rotating moving arm (9), transfers the rotating motion and the work to the engine shaft and the CPC piston (7).

- At the same time, the other side of the CBC piston (8) pushes the burned gases of the previous combustion cycle to the atmosphere, through the exhaust port (12). 


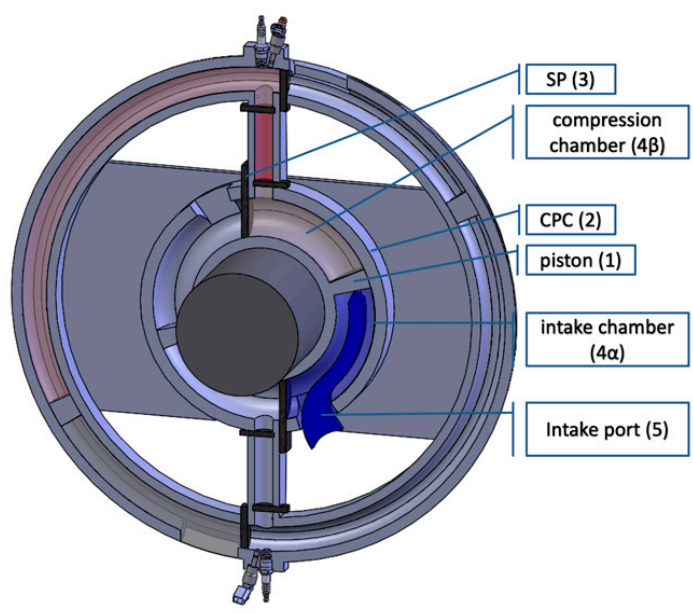

(a) intake and compression process

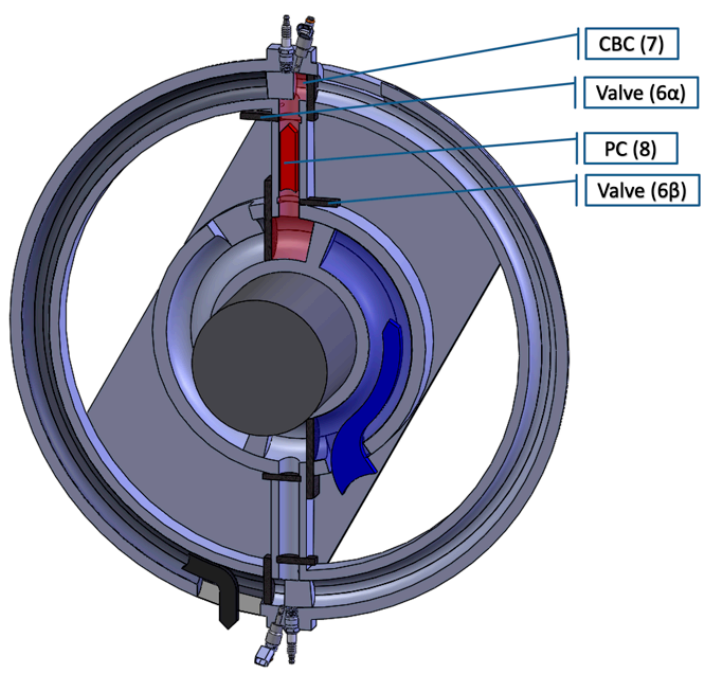

(b) air transfer to the combustion chamber (CBC)

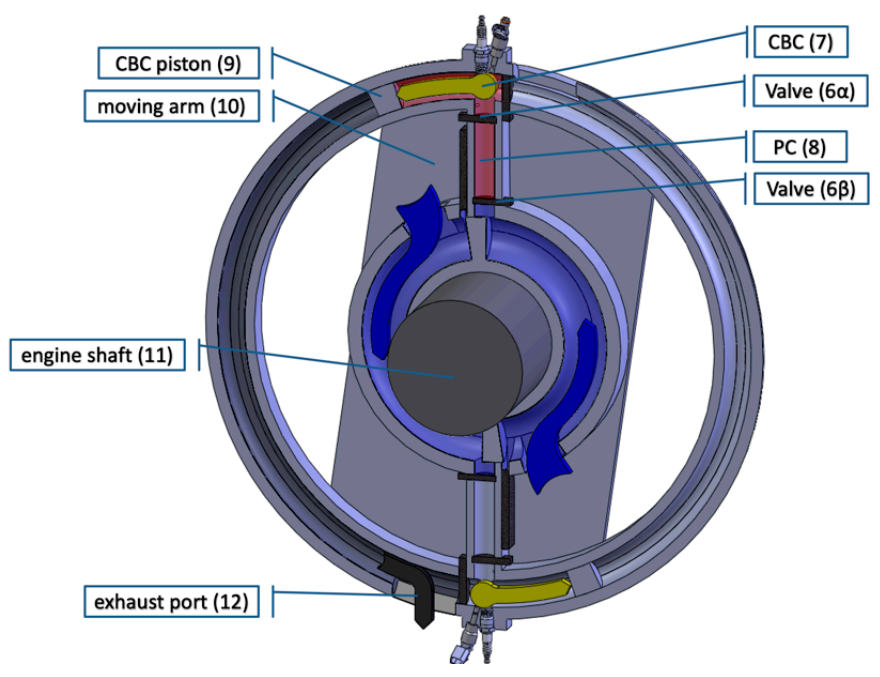

(c) ignition-expansion process

Figure 2. SARM engine operating phases.

By this brief description of the SARM engine operation, a number of its special features become apparent, which form the basis of its advantages compared to the conventional reciprocating piston engines.

A major difference between the SARM engine and all conventional SI engines (either reciprocating or rotary) concerns the operation of the pistons. While in conventional four-stroke reciprocating engines the same piston performs periodically the four different strokes (intake, compression, expansion, exhaust), in the SARM engine each piston performs continuously the same two individual strokes, and the same stroke takes place every time at the same side. The intake process takes place at the back side of the compression (CPC) piston, while the compression is realised with its front side. Similarly, the expansion takes place at the back side of the combustion (CBC) piston, while the burned gases are exhausted to the atmosphere by its front side. Thus, all four strokes (intake, compression, expansion, exhaust) occur simultaneously with one pair of $\mathrm{CPC}$ and $\mathrm{CBC}$ pistons. These mean that the $\mathrm{CBC}$ piston undergoes only the high pressure-high temperature processes, remaining "hot", and the CPC piston 
operate in the low pressure-low temperature part of the cycle, remaining "cold". This offers an extra flexibility to the SARM engine, which is the separate optimization of the materials for each piston, also taking into account that they rotate in significantly different radii.

The concentric design is another special feature of this rotary engine. At first, the rotary operation eliminates the mechanical losses imposed by the transformation of the piston's linear motion and the crankshaft's rotational motion. In addition, one main moving part is responsible for all processes, which rotates concentrically with the engine shaft. This configuration minimizes the parts of the engine, drastically reducing its complexity and weight. On top of that, the SARM engine design has an additional positive characteristic; the pressure force applied on the piston during combustion and expansion is always vertical to the piston (see Figure 3). This means that this force is always transferred tangentially to the outer surface of the engine shaft and $100 \%$ of this force always produces torque. Contrary, in a conventional reciprocating engine, the force producing torque on the crankshaft is only a portion of the pressure force on the piston, depending on the instantaneous position of the crankshaft. Thus, for the same produced torque, the SARM engine needs to develop lower combustion pressures, enhancing higher efficiency and allowing for lighter and thinner combustion chamber walls. The higher efficiency is translated to lower fuel consumption, while the lower combustion pressures result to lower temperatures too, with a subsequent positive effect on NOx formation.

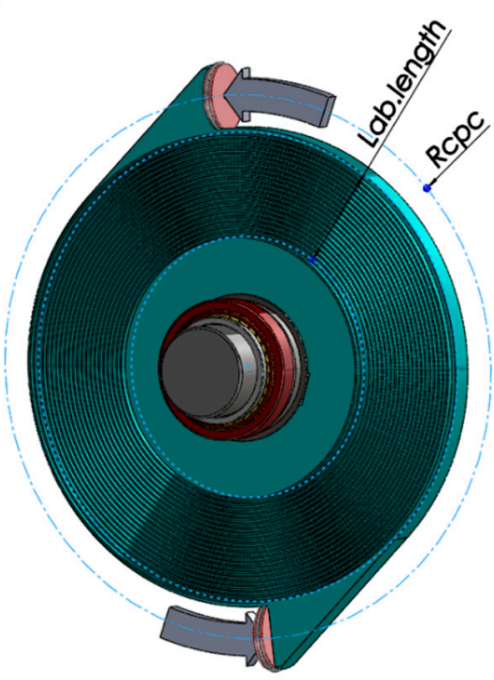

Figure 3. The pressure force applied on the piston is always vertical.

\subsubsection{Advantages of the SARM Engine}

Overall, the advantages of the SARM engine can be summarized as follows:

- Simple design and less moving parts than the reciprocating engines. Fewer engine components reduce also the need for maintenance.

- Up to four times smaller and lighter in weight than the four-stroke reciprocating engines.

- There are no mechanical losses and inertial forces from the conversion of reciprocating to rotational motion. The absence of reciprocating motion eliminates oscillations [23].

- No change in the direction of the piston motion, the characteristic piston "slap" occurring at the TDC (Top Dead Center) of a conventional reciprocating engine, causing wear of the piston skirt and the bore, and noise [24].

- Pressure force on the piston is always tangential and is fully exploited for power production. In addition, the applied forces are only in the direction of the flow allowing the piston sleeve to be very short (see Figure 4).

- Lack of lubricant inside the compression and combustion chambers. As it is well-known, the lubricant may also contribute to the unburned HC emissions of an engine [23]. 
- The symmetry of the SARM design minimizes the need for counterweights.

- Up to $15 \%$ lower fuel consumption, taking advantage of the higher efficiency, as explained previously [25].

- Great potential for lower NOx emissions, due to the lower combustion temperatures. In addition, the compression chamber can be designed in such a way that the heat dissipation to the coolant (or the environment) is enhanced and the charge air remains at a lower temperature (thus higher density) before entering the combustion chamber.

- Decoupling of the main engine processes. Although this is an inherent characteristic of any split engine, and not only of the current one, it is important to be mentioned here that it offers great advantages compared to the conventional reciprocating piston engines. As described previously, each process occurs at a separate volume and on a specific side of each piston, enabling thermodynamic optimization, as well as selection of different materials and application of individual surface treatment.

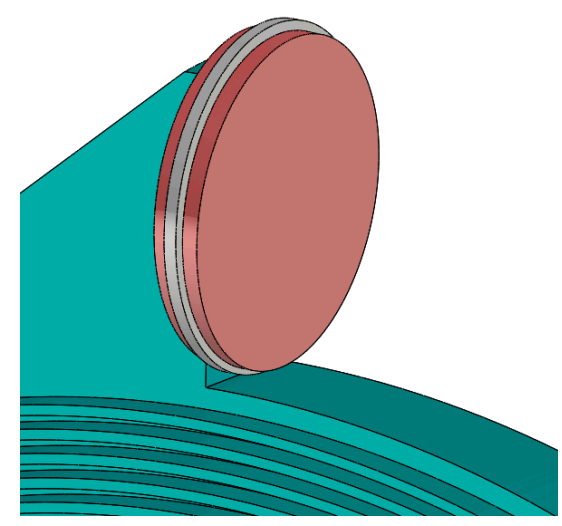

Figure 4. The piston sleeve is very short.

\subsection{Objectives and Methodology}

After the brief presentation of the engine and its main technical features and advantages, this section describes the specific objectives of the current study. These are:

- Investigating the most effective labyrinth seal to seal the compression chamber and

- Investigate the compression chamber's design

\subsubsection{Sealing Geometries}

While the SARM engine presents some particular advantages, a major concern is the sealing of the gap between its rotating arm and the engine block parts. This is a common issue in gas turbines, as well. Even though there are many advanced sealing systems developed last years, labyrinth seals remain a widely used solution for the rotating machineries [26] because they are simple, reliable, operate in high temperatures and for a wide range of pressure ratio [27]. For these reasons, this sealing method is used and optimized for the needs of the SARM engine.

Labyrinth seals consist of a series of cavities connected by small clearances, avoiding the contact of the moving with the stationary parts of the sealing device (see Figure 5). The high pressure of the flow is reduced due to friction through the clearance and walls, because the cavities dissipate the kinetic energy of the flow. This gradual pressure reduction continues at each cavity until the exit of the flow through the last one. Key operating parameters are the pressure ratio between the inlet and outlet of the flow from the sealing system, and the clearance (gap) between a moving tooth and the stationary wall above this tooth. 


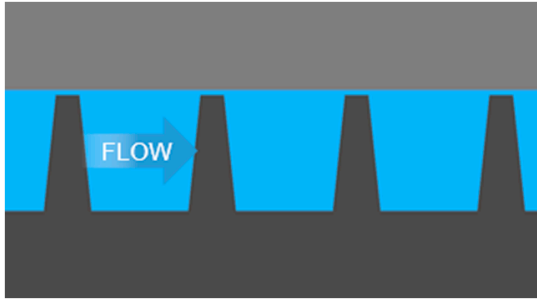

(a) One-sided straight labyrinth seal.

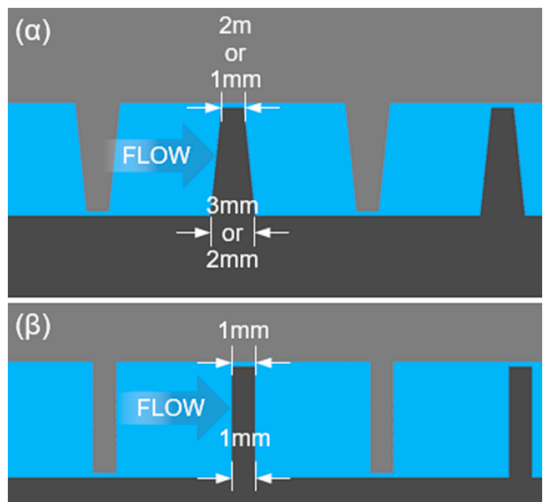

(b) Tooth interlocking labyrinth seal

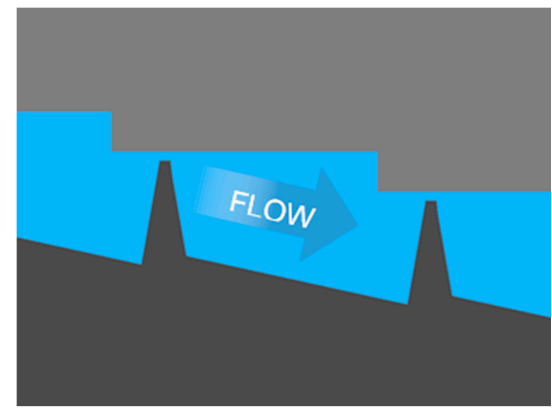

(c) Stepped labyrinth

Figure 5. Labyrinth geometries examined.

For the purposes of the current study, the following labyrinth geometries are investigated (Figure 5):

1. One-sided straight labyrinth seal (Figure 5a) where all teeth are located on the rotating part (motion transfer arm). This kind of seal is very simple to manufacture and very cheap because conventional materials may be used for its construction. The first designs of such labyrinths used large chambers between two neighbouring teeth. Moreover, relatively long teeth can be easily damaged, destroying the chambers (or pockets) between them.

2. Tooth interlocking labyrinth seal (Figure $5 b$ ). This seal usually employs a labyrinth with more teeth and a higher pressure drop. This kind of labyrinth sealing has not been investigated thoroughly by many researchers [28,29]. For this kind of labyrinth, the size of the teeth is also investigated, which practically modifies the size of the chamber between the teeth. The following teeth dimensions are investigated:
a. $\quad 3 \mathrm{~mm}$ at the teeth basis and $2 \mathrm{~mm}$ at their edge
b. $\quad 2 \mathrm{~mm}$ at the teeth basis and $1 \mathrm{~mm}$ at their edge
c. $1 \mathrm{~mm}$ at the teeth basis and $1 \mathrm{~mm}$ at their edge

3. Stepped labyrinth (Figure 5c). These seals are advantageous when the clearance cannot be small [30]. For instance, this kind of seal is used in the compressor eye seals [31].

\section{Mesh Description}

The first step after the description of the geometries is the construction of the final mesh that will be used for the CFD simulations. Even though the final mesh is created automatically by the CONVERGE CFD solver, the user has to define some parameters for the mesh density. The user can 
separate the model in different regions or tell the solver to refine the mesh near specific boundary conditions (in this case, walls). These parameters are used for the grid-independence investigation of the solution.

If the effect of rotation is excluded, then a 2D rig can provide similar results with the ones from an axisymmetric 3D rig [32]. In gas turbines, like in any rotating device, the one seal side is rotating and the other is stationary. It has been found that the rotation effect becomes significant only when the rotating speed becomes very high. More precisely, the influencing factor is the ratio between the teeth's circumferential speed and the speed of the flow. When this is very high, then the rotation effect becomes significant [33]. Therefore, static rigs are mostly preferred for this reason [30].

Not only the turbulence model introduces an error, but also two additional effects influence the results' accuracy. The first is the discretization parameter, which affects the prediction accuracy when coarse grids are used. In order to minimize this error, after running some simulations, it was concluded that using 1,000,000 cells is the best approach. This is also proven by the results in Figure 6, which presents the influence of the grid resolution on the discharge coefficient (DC) and mass flow rate for the case of one-sided labyrinth. The same investigation concerning grid independency was conducted for all the geometries considered in this study, concluding that the accuracy of the results was acceptable when using meshes of more than $1,000,000$ cells.

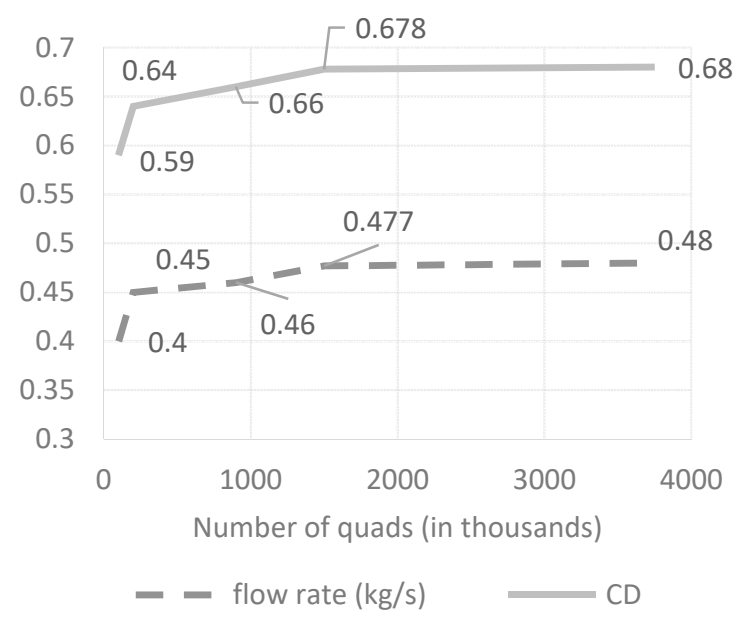

Figure 6. How the discharge coefficient (DC) and the mass flow rate changes with the grid resolution.

The second influence comes from the boundary layer of the wall. The initial assumption was that the high pressures would develop velocities that are too high, thus the influence of the boundary layer would be negligible. However, a sensitivity analysis conducted showed that the boundary layer has a significant effect. Particularly in the case of a very fine grid, the closest-to-the-wall grid point falls below values of $y+=30$. In this region, the logarithmic law is not valid $\{7\}$. An ANSA (BETA CAE Systems) pre-processor was used for the creation of the geometries.

\section{CFD Model Setup}

The numerical simulations of the labyrinth seal flow for the different geometries were executed with the commercial software CONVERGECFD, solving the time-averaged Navier-Stokes equations. The advantage of this software is the fast setup and solving of many complicated design configurations because the mesh is created automatically.

In the current investigation, the walls were considered smooth and with zero slip. This assumption was made in order to simplify somehow the problem and facilitate the faster convergence of the code. It is acknowledged, however, that the wall roughness would increase the circumferential velocity of the fluid before entering the seal. 
Another simplification of the problem came from the assumption that the working fluid is air, which is assumed as an ideal gas, in a steady and adiabatic flow. This approach is a common approach for labyrinth seal investigations [34-36].

The parameter used to confirm convergence was the Root Mean Square residuals (RMS) of the momentum, energy, mass and turbulence equations and the limit value applied as convergence criterion was set to $10^{-6}$. Turbulence models and the relevant assumptions are summarized in Table 1 .

Table 1. CFD model setup.

\begin{tabular}{cc}
\hline Setup & Selected options \\
\hline Solver & Navier-Stokes Pressure-Based \\
PISO \\
Convergent Criterion & Periodic Boundary/Sector (pie shape) \\
3D & Steady, ideal gas compressible, turbulent \\
Flow Assumption & Time based, SST k- $\omega$ \\
Models & Air (ideal gas) \\
Materials & 0 \\
Operating Pressure (bar) & 50 \\
Pressure-inlet (bar) & 700 \\
Inlet Temperature (K) & 2 \\
Pressure-outlet (bar) & 450 \\
Outlet Temperature (K) & Adiabatic, absolute roughness $=0$, no-slip \\
Wall properties & Transient \\
Solution Methods Scheme & Second Order Upwind \\
Spatial Discretization & Hybrid \\
Solution Initialization & PISO tolerance 10-6 \\
Convergence criterion &
\end{tabular}

As mentioned above, the flow was considered adiabatic. This assumption is based on the study of Mirzamoghadam and Xiao [37] who conducted a numerical study on an industrial gas turbine with labyrinth seal. They compared the temperature and pressure in the labyrinth, for an adiabatic wall and a wall with heat transfer. They concluded that the profiles do not change with the heat transfer. They verified their conclusion also with steady-state temperature and static pressure measurements in the labyrinth. Table 1 summarizes all parameters and values used for the CFD model setup.

Thorat and Chids showed that the whirl frequency depends significantly on the DC of the labyrinth seals when the Mach number approaches unity [38], or when there is an inlet pre-swirl or when the pressure is very high $[38,39]$. Additionally, pre-swirl and the rotor whirl speeds have a small effect on the leakage for one-sided and stepped labyrinths [29].

The SST k- $\omega$ equations were used for the turbulence model. The compressibility effects were considered as Mach number approaches 1.0. The SST k- $\omega$ model was chosen over k- $\varepsilon$, as it is more used for complex boundary layer flows with adverse pressure gradient and separation. This is very common for external aerodynamics and turbomachinery.

As mentioned above, the desired convergence target was set to $10^{-6}$ (RMS residuals for the momentum, mass, energy, and turbulence equations). The net flux imbalance was less than $1 \%$ of the smallest flux in the whole boundary domain for all converged cases. Since DC and pressure ratio will present all calculation results, the setup of the inlet and outlet boundary conditions does not matter significantly [30].

The good setup of the solver is verified by the fast convergence of all solution-cases.

\subsubsection{Compression Chamber's Design}

Simulation Model Setup

The first step is the 3D CAD design of the volume included inside the compression chamber and the labyrinth, which is prepared in ANSA (BETA CAE Systems). The major parameter to begin 
with is the size of the toroidal compression chamber, quantified by its outer diameter (Rcpc, Figure 3). The principle idea is to keep the compression chamber as close as possible to the engine shaft (i.e., small Rcpc). However, the sealing system limits the minimum possible value of this diameter because there is a minimum length of each labyrinth seal type that makes the labyrinth effective (Lab.length, Figure 3). The labyrinth must be long enough to prevent any leakage of the working medium from the chamber to the environment. The above study tests the labyrinth in the most extreme thermodynamic conditions developed inside the combustion chamber. The compression chamber's design study tests only the two most effective labyrinths for sealing the compression chamber from the environment; the stepped labyrinth seal and the tooth-interlocking or two-sided labyrinth (Figure 5). The stepped labyrinth needs a shorter length to drop down the pressure, while the two-sided labyrinth needs a longer path. Therefore, the stepped labyrinth is characterised in the following analysis as the Long-Sealing system (LS) and the two-sided labyrinth as Short-Sealing (SS). Even though the most logical thought is to use the stepped labyrinth, since it is a shorter (more efficeint) labyrinth, this labyrinth needs a thicker body for the motion arm and the housing due to the steps (Figure $5 \mathrm{c}$ ). The longer the stepped labyrinth, the higher the first tooth from the last one; this is translated to a thicker motion disc (Figure 3). On the other hand, the two-sided labyrinth is longer but its length does not influence the thickness of the motion disc. Like Figure 5a shows, all teeth are on the same height-level.

After defining the 3D fluid-volume geometry inside ANSA, follows the definition of the boundary conditions. The fluid-volume is a closed volume, defined by the walls of the housing, sliding port, piston and labyrinth, as well as the inlet boundary on the intake port and the outlet boundary at the end of the labyrinth. Here, the only assumption is that the sliding port seals watertight when it closes. When the sliding port opens, a very small percentage of the trapped air leaves the chamber $(10 \%)$ through the intake port, but eventually comes back when the intake process starts again. The complexity of the fluid's design (chamber with piston, sliding port and labyrinth) does not allow for the creation of an understandable 3D model view. On the other hand, ANSA topology tools offer an easy and fast preparation of the final watertight 3D model. Before exporting the STL file to the solver, the minimum number of nodes is essential to keep the final file as small as possible, for making the automatic procedure of mesh generation inside the solver faster.

The CONVERGE CFD solver creates both the surface and volume mesh automatically and the only requirement is to input the STL file. It is crucial to define all 3D geometrical details with the minimum number of nodes. A very-fine STL mesh avoids intersections of the parts, especially when there are many curvatures in the geometry. On the other hand, a very fine mesh in regions where there are only flat surfaces can make the STL file heavy which makes the simulation process slower; the higher the number of nodes, the slower the generation of the mesh during each time-step.

Since CONVERGE CFD can read only STL files to recognise the model's geometry, the model has to be initially meshed inside ANSA with the STL mesh algorithm. The meshing tools of ANSA allow for the automatic creation of an STL mesh with the least possible nodes in flat surfaces and a controllable number of nodes in the curved edges. The final quality-control is to smooth all curved surfaces with the ortho-triangle mesh. This is an automatic procedure with no additional time required by the user.

CONVERGE CFD is mainly designed for simulations in internal flows and thermal engines of any nature, such as reciprocating or rotary ones, turbomachines, pumps and compressors, boilers and burners. It is ideal for highly transient simulations with a variable mesh. Its main advantage compared to other CFD solvers is the automatic creation of the grid. This solver creates a perfect rectangular structured grid based on simple user-defined parameters [40] (see Figure 7). Moreover, the user can use a rotation angle instead of time, which is ideal for rotational devices like the SARM engine. 


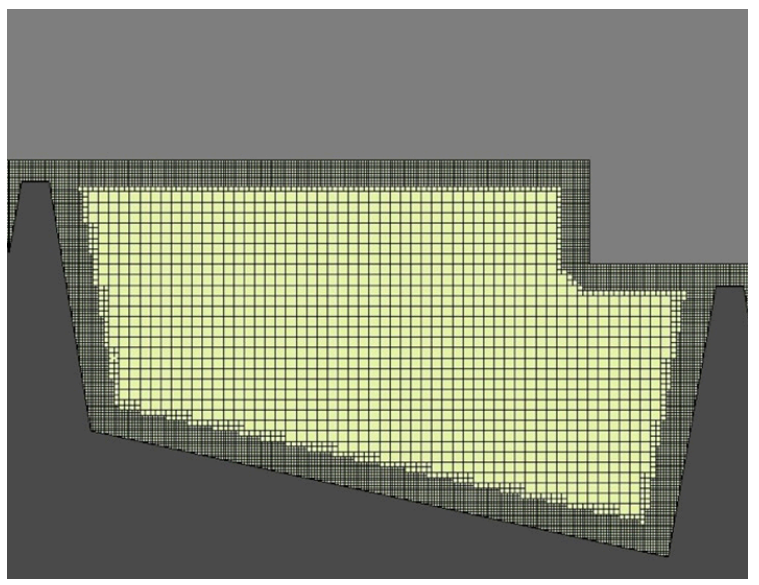

Figure 7. The mesh created by the "CONVERGE CFD" solver for the stepped labyrinth seal.

The turbulence model used for this compressible flow is k-e RNG. Although the RSM model is ideal for simulating flows with intense vortices, pressure waves, high turbulence and directional changes (such as curved pipes, cyclones), a compromise was necessary between the simulation time and accuracy of the results due to the high computational cost. The k-e RNG model is widespread in four-stroke Internal Combustion Engines (ICE), and after a benchmark between the two turbulence models, the results showed that there is a small difference in the solution, but with an exceptionally longer simulation-time for the RSM [41]. Finally, the META post-processor was used for the analysis.

\section{Model Optimization}

Before running any case, the time, grid and iteration cycle independency is assessed. According to CONVERGE CFD recommendations, for ICEs it is essential first to run at least 5 to 30 iterations [40] in order to obtain a solution that is not affected by the operating cycles.

Beginning with the time step, the solver ensures a time-independent study by using a variable time-step. By choosing a minimum of $10^{-8}$ and a maximum of $10^{-3} \mathrm{~s}$ time-step, for $3000 \mathrm{rpm}$, the solver uses the optimum value according to the moving mesh velocity and pressure change rate.

For the grid size effect, it was found that the result using a grid of 400,000 cells deviates only by less than $2 \%$ from the finest grid (of 1,100,000 cells). At the same time, this coarse grid requires only $40 \%$ of the computational time of the finest grid.

After choosing the right time-step and grid-size, the model is executed iteratively for a number of cycles. As presented in Figure 8, after four cycles the deviation in the maximum calculated pressure and temperature drops below $1 \%$ between two consecutive cycles. Thus, there was no need to run more than five cycles.

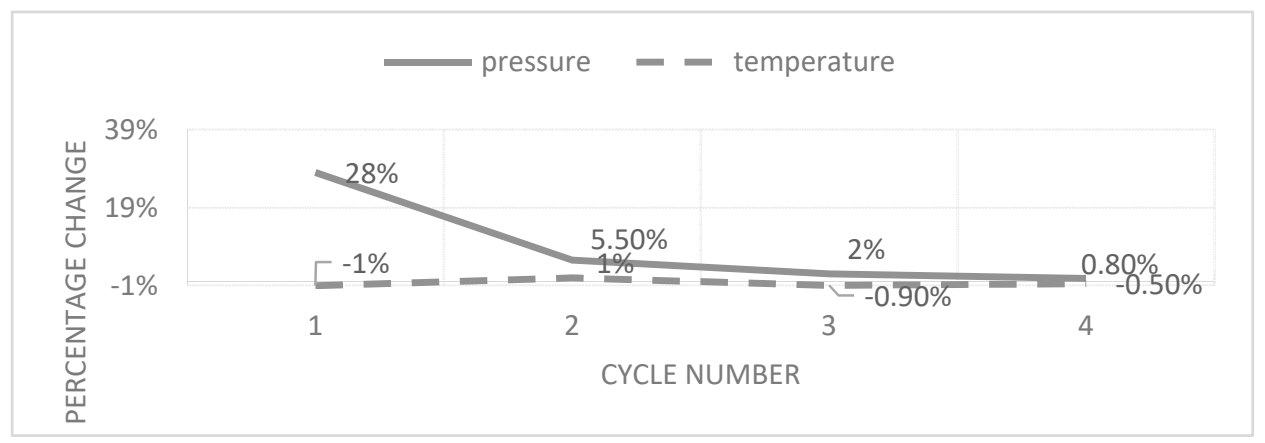

Figure 8. Effect of the engine rotations' number on the maximum temperature and pressure showing the cycle independency. 


\section{Results and Discussion}

\subsection{Sealing Optimization}

Pressure contour plots were produced for all the different labyrinth geometries. According to previous research [30], when the clearance is sufficiently small, then the pressure distribution is uniform along the cavities. On the other hand, in the case of a larger clearance, the pressure drop is relatively greater in the first cavity. In the geometries examined in this study, the clearance is sufficiently small $(200 \mu \mathrm{m})$, thus the uniform pressure drop is expected, validating the final results of the CFD model.

The following figures present the gas velocity contours inside the different seal geometries:

- Figure 9: one-sided straight labyrinth

- Figure 10: tooth-interlocking labyrinth with $1 \mathrm{~mm}$ (top), $2 \mathrm{~mm}$ (middle) and $3 \mathrm{~mm}$ (bottom) basis thickness

- $\quad$ Figure 11: stepped labyrinth

In all cases, the CFD model converged according to the criteria set in the previous section, producing the streamlines inside the chambers of the different labyrinth types. The various geometries generate different flow fields, while in all the cases the working fluid exits finally from the tooth at a high velocity. For each individual geometry, the flow field is similar among the intermediate chambers.

In the cases of the one-sided straight labyrinth (Figure 9), the tooth-interlocking labyrinth (Figure 10) and the stepped labyrinth (Figure 11), the high velocity streamlines are located at the top side of the last chamber.

In the case of the stepped seal, the large step distance combined with the sufficient step height increases the dissipated dynamic energy inside the cavity, as compared to any seal with straight shape. This complicated flow structure incurs a larger pressure drop for a given mass flow. On the other hand, a disadvantage of the stepped seal is its larger overall seal height. Hence, the overall size of the stepped seal is larger than that of any straight seal.

Velocity

Velocity contours $[\mathrm{m} / \mathrm{s}]$

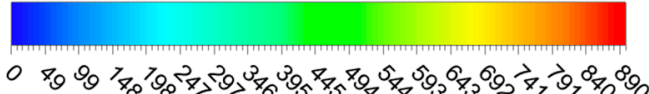
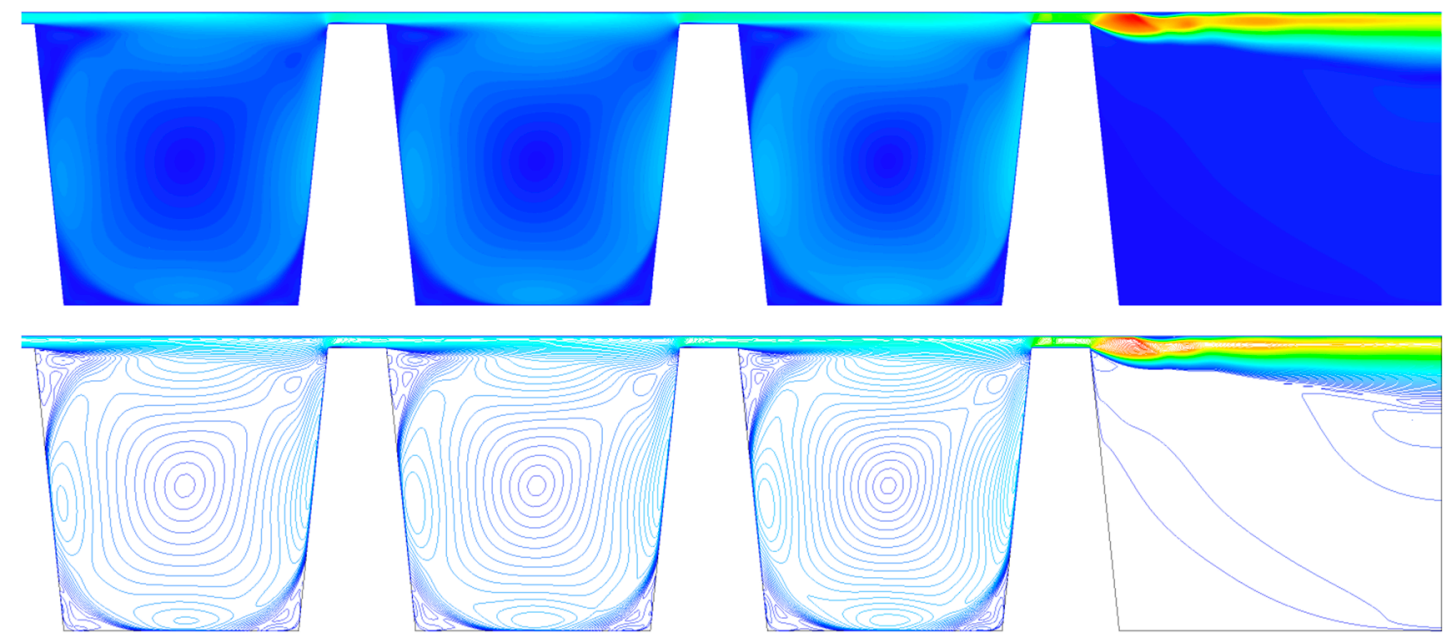

Figure 9. Velocity contours inside the one-sided straight labyrinth. 
Velocity contours $[\mathrm{m} / \mathrm{s}]$

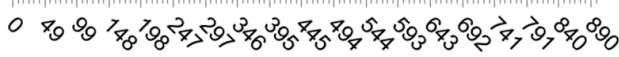
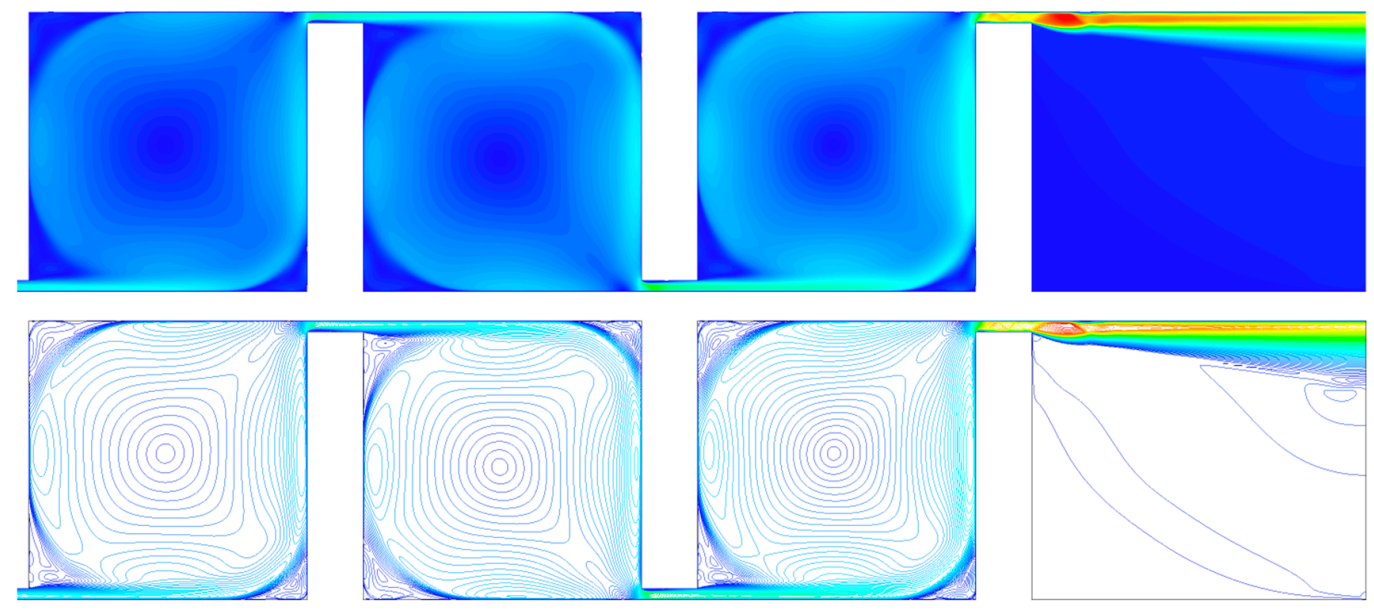

(a)

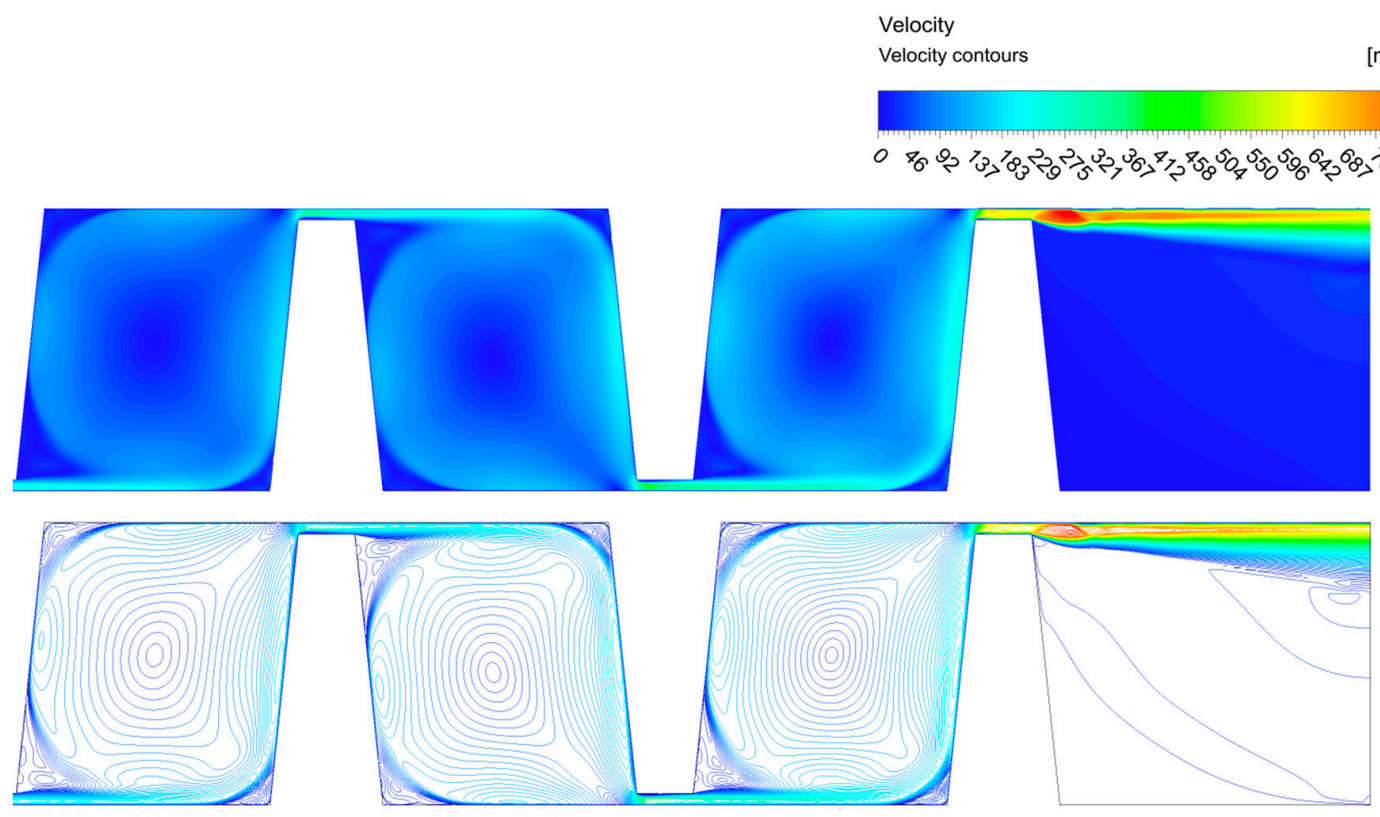

(b)

Figure 10. Cont. 


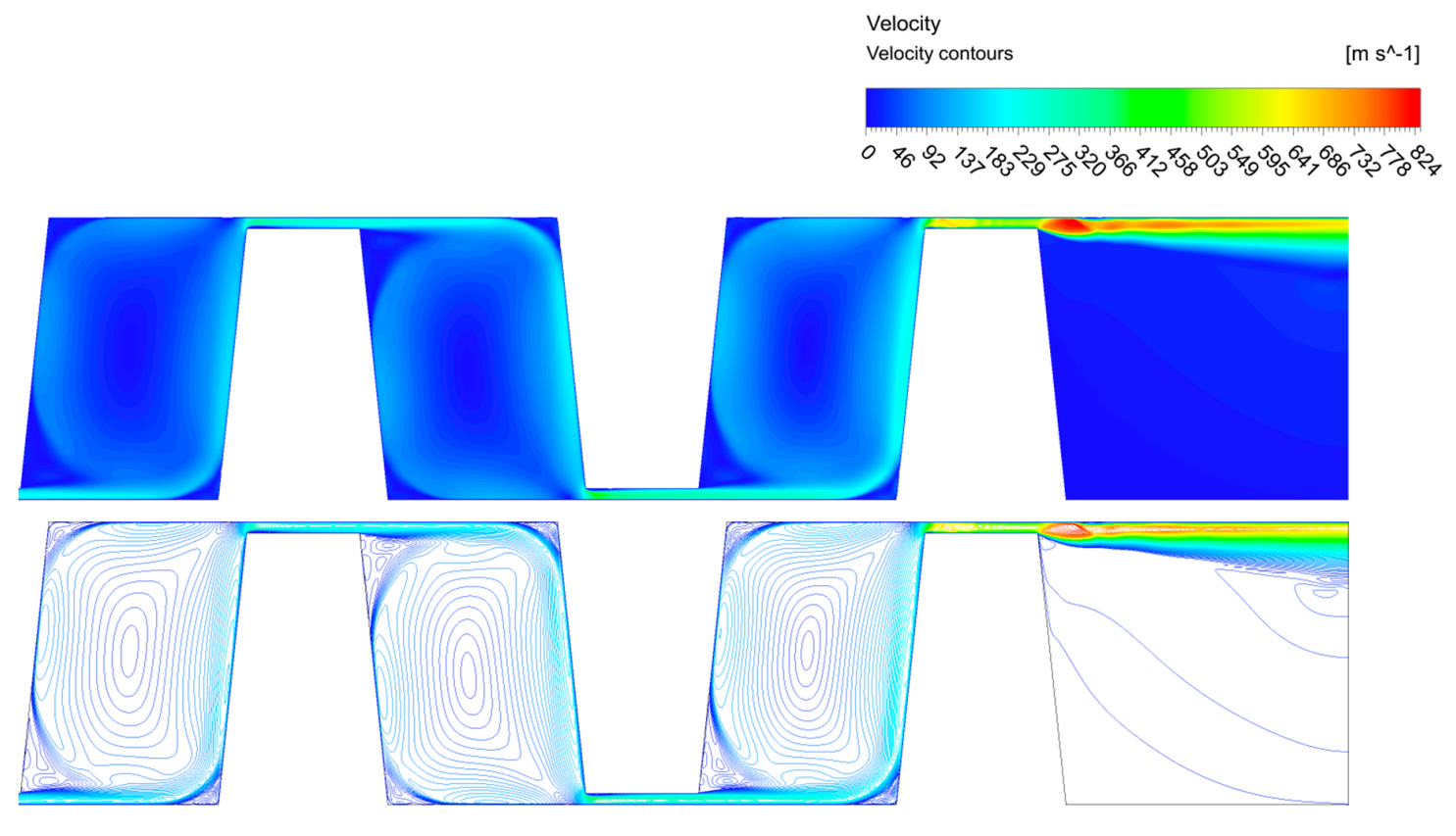

(c)

Figure 10. Velocity contours inside the tooth interlocking labyrinth with $1 \mathrm{~mm}(\mathbf{a}), 2 \mathrm{~mm}(\mathbf{b})$ and $3 \mathrm{~mm}$ (c) basis thickness.

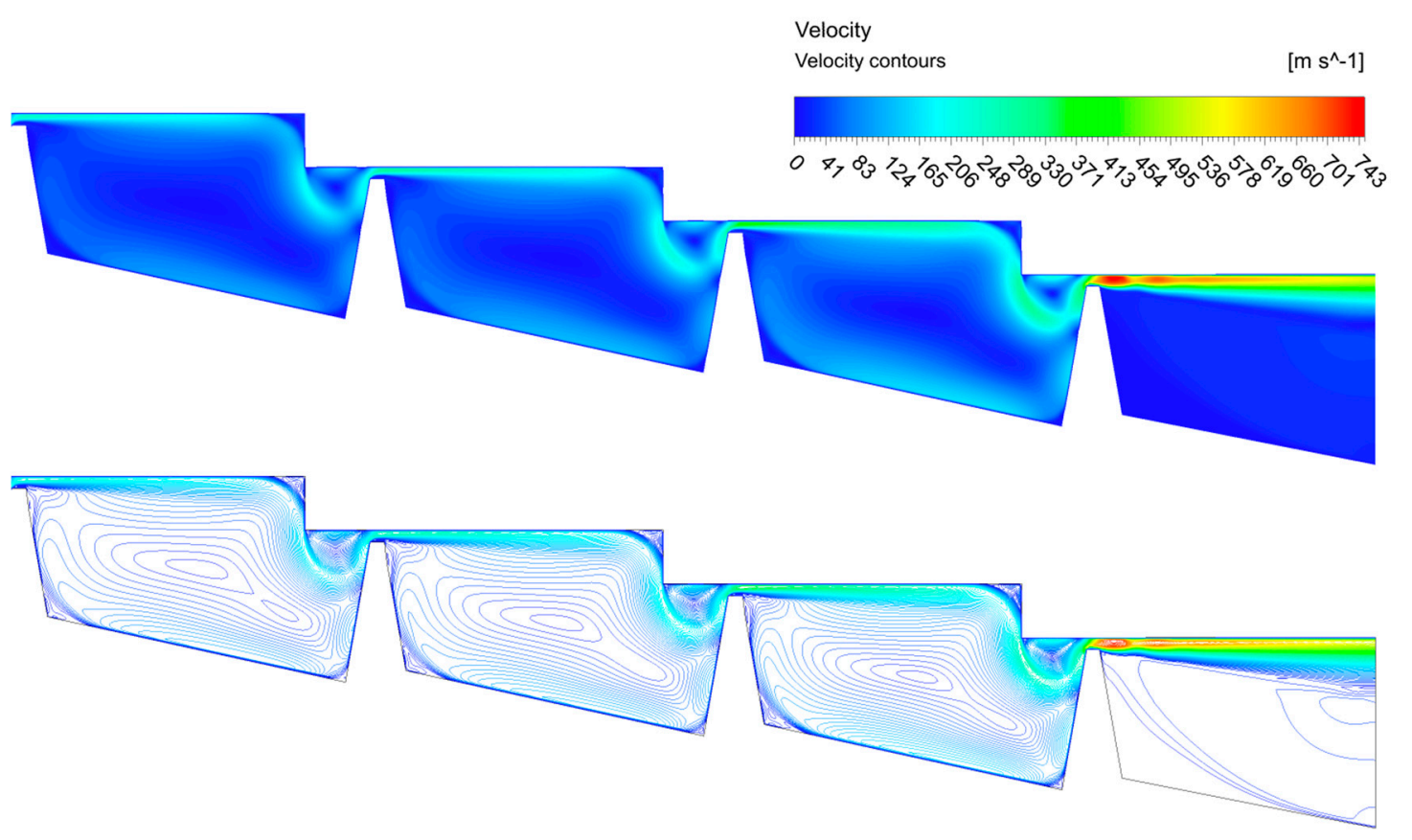

Figure 11. Velocity contours inside the stepped labyrinth.

In order to assess comparatively the different labyrinth geometries, and since such a direct comparison is not straight-forward with the velocity contour plots, the pressure drop across the seals is examined, as shown in Figure 12. A significant pressure drop is observed exactly after each tooth tip. Inside each cavity, the pressure remains almost constant and a small pressure rise is observed at the leading edge of each tooth. The latter is the result of the partial blocking of the flow at the tooth, reversing the flow back to the chamber. 


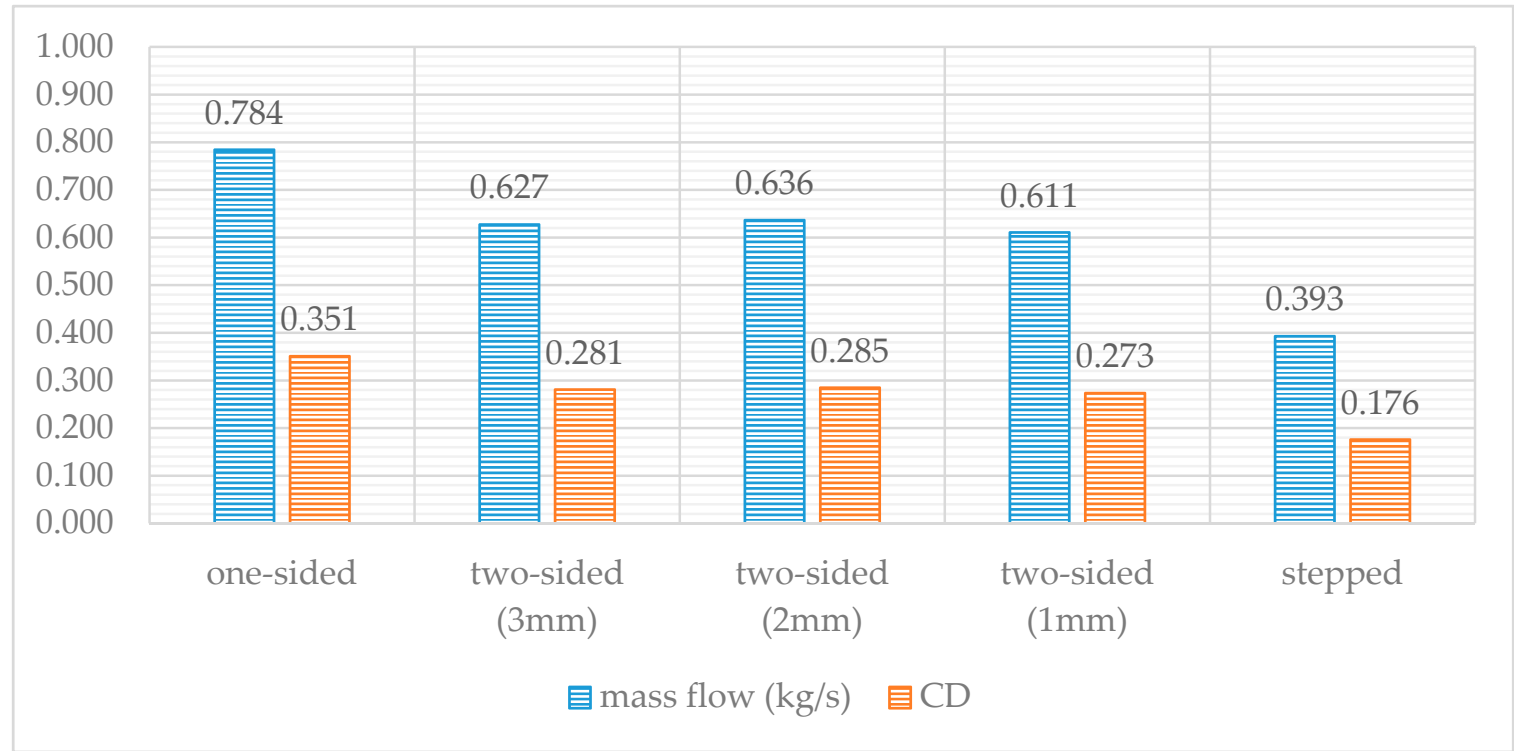

Figure 12. Influence of geometry configuration on the computed discharge coefficient and the mass flow rate.

For the quantification of the sealing efficiency, the (dimensionless) DC is determined. This coefficient expresses the fraction of the leakage mass flow to the ideal mass flow rate for an isentropic expansion through a single nozzle [42]. This means that the target is to obtain a low value for this coefficient.

As shown in Figure 12, the average DC of the stepped seal is lower than that of most of the straight seals, indicating that the leakage performance of this geometry seal is better. However, this type of labyrinth is characterized by a more expensive construction, as well as by larger overall height.

The above observations indicate clearly that for the specific operating conditions (pressure ratio 25 and temperature $700 \mathrm{~K}$ ), the stepped labyrinth has the best efficiency, with a DC equal to 0.38 and the lowest mass flow rate. On top of this, according to Waschka et al. [33], the rotation results in a further reduction of the DC, when the circumferential velocity of the rotor exceeds the axial velocity of the flow. This means that at high engine speeds, the sealing efficiency is expected to be even higher.

\subsection{Compression Chamber Configuration}

The first output of the model is the examination of the compression chamber (CPC) configuration. According to previous work [20], the target is to keep the CPC as close as possible to the engine shaft. However, the two different sealing systems require a different Rcpc (Figure 3). The stepped labyrinth (Short-Seal: SS) uses the minimum possible Rcpc and the two-sided (LS) the maximum possible. However, the $\Delta R c p c$ (Rcpcmax-Rcpcmin) is limited to $10 \mathrm{~mm}$ due to the under constraints of the engine's design for keeping the overall size within specific limits. The outer diameter of the engine cannot exceed the $200 \mathrm{~mm}$ in order to use CNC machining with low cost. Here, the comparison of the two chamber's configurations is based on the final peak pressure at the end of the compression process (Table 2).

Table 2. Optimization of intake port and sealing system.

\begin{tabular}{ccccc}
\hline \multirow{2}{*}{ Configuration } & \multicolumn{2}{c}{ CFD } & \multicolumn{2}{c}{ Isentropic process } \\
\cline { 2 - 5 } & Peak p (bar) & Peak T (K) & Peak p (bar) & Peak T (K) \\
\hline LS.II & 23.3 & 587 & 28.9 & 775 \\
SS.II & 25.6 & 617 & 28.9 & 775 \\
SS.OI & 26.9 & 614 & 28.9 & 775 \\
\hline
\end{tabular}


The second output of the model concerns the optimization of the shape of the intake port in order to maximise the volumetric efficiency. Two intake port designs are considered: a rectangular (i.e., the Initial Intake, II) and another one that offers the optimal shape for the most efficient charge of the compression chamber with fresh air (i.e., the Optimized Intake, OI).

Table 2 presents the results of the CFD calculations and the ones assuming isentropic process. Initially, the sealing system is assessed (LS vs. SS) and the best is simulated with the optimized intake port (OI).

As shown in Figure 13, the combination of the optimized intake-port and the short sealing system can reach up to $15 \%$ higher peak pressure, as compared to the initial configuration.

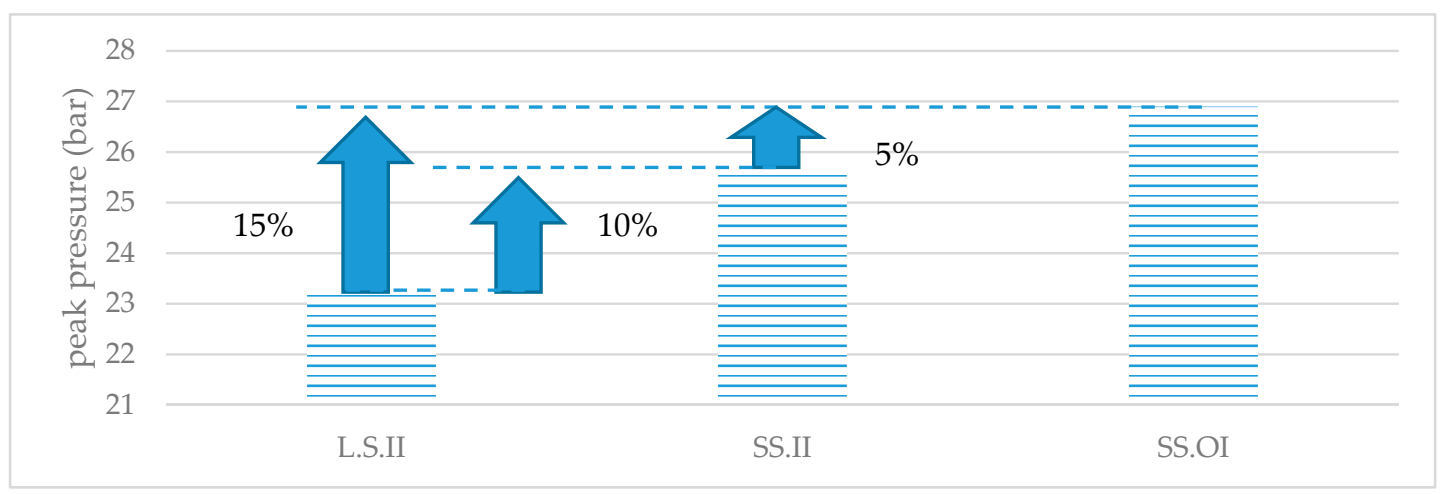

Figure 13. Optimization of intake port shape and sealing length.

The following figures present the development of pressure and temperature in the intake and compression chambers. Beginning with the intake chamber, Figure 14 highlights the advantageous configuration of the optimized intake port combined with the short sealing system (SS.OI). Two positive aspects are revealed. On the one hand, the SS.OI configuration results in higher pressure, almost throughout the complete intake process. This enhances the charging of the CPC with air and leads to a higher peak pressure at the end of compression. On the other hand, the pressure in the intake chamber with the SS.OI configuration is almost constant throughout the intake process, minimizing any negative flow effects due to pressure gradient. The lower pressure at the beginning of the intake process with the other two configurations (both with the initial intake port shape) shows clearly that the initial intake port design causes a pressure drop. Concerning temperature in the intake chamber, there is only a slight difference between the different configurations.

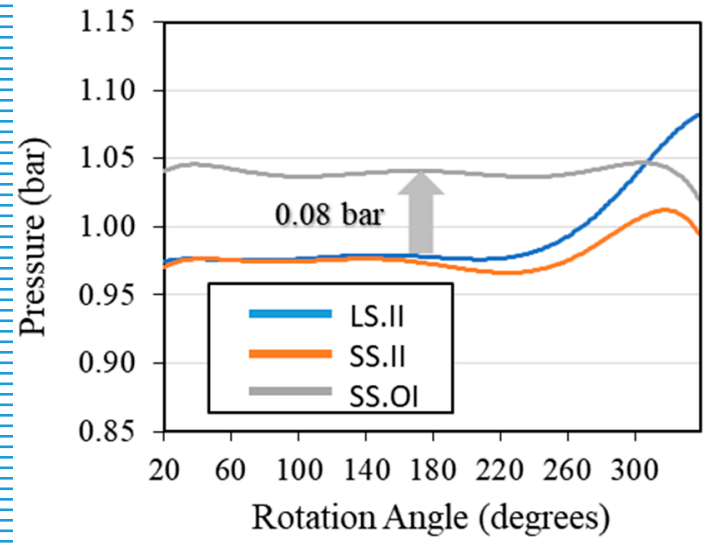

(a)

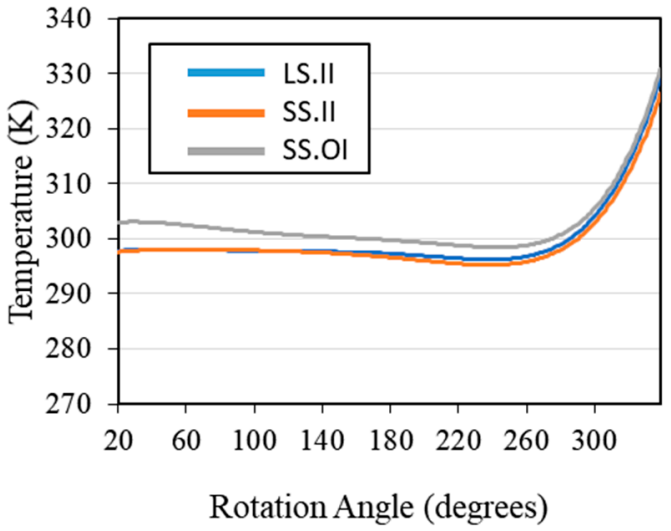

(b)

Figure 14. Pressure (a) and temperature (b) development in the intake chamber. 
Pressure and temperature development in the compression chamber are presented in Figure 15. The differences between the three configurations examined here are minimal with an obvious difference only on the peak pressure and temperature, as already shown in Table 2.

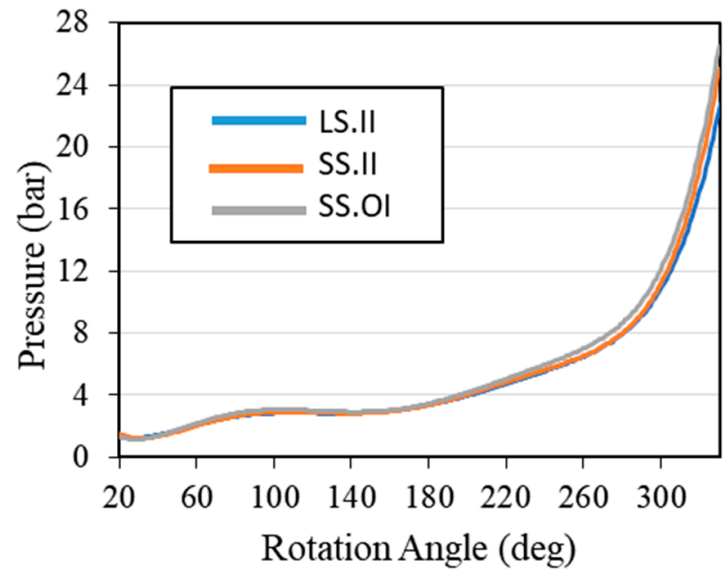

(a)

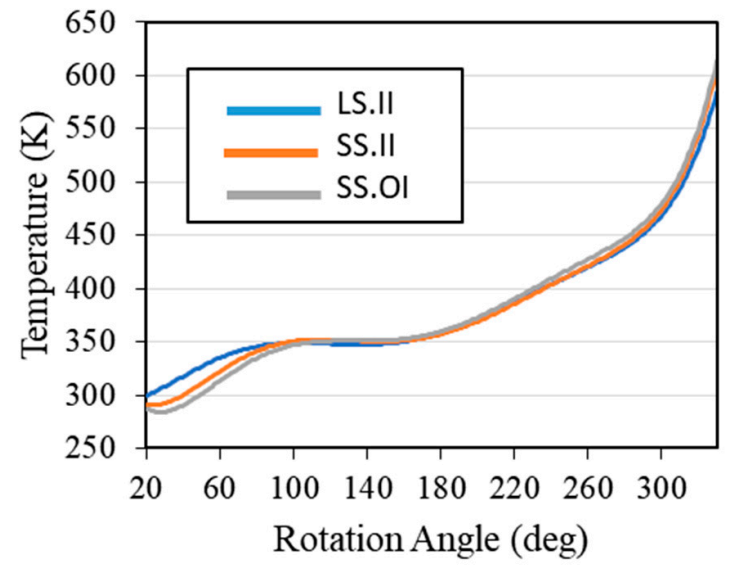

(b)

Figure 15. Pressure (a) and temperature (b) development in the compression chamber.

\section{Conclusions}

The current work studies two particular features of a novel rotary engine. The SARM engine presents a number of advantages as compared to conventional reciprocating piston engines. The most important advantages are its simple design and the fewer moving parts that are directly translated to smaller and lighter construction. The main difference from other rotary engines is that the processes are decoupled and are realized in different chambers, allowing for individual optimization. Possible advantages are lower fuel consumption and great potential for significantly reduced NOx emissions.

In the present study, the compression chamber design and the sealing system were investigated. For that aim, simulation models were setup in CONVERGECFD software. The required meshes for solving the momentum, mass, energy and turbulence equations were constructed automatically by the software and the relevant assumptions were made.

Two parameters of the compression chamber were examined, namely the intake port design and the length of the sealing system. The initial and the optimized design were examined for the former, while a short and a long sealing system were considered.

At first, the compression chamber (CPC) configuration was investigated. Previous work shows that keeping the CPC as close as possible to the engine shaft is beneficial $[20,25]$. The limiting parameter of the minimum rotation radius of the CPC piston, however, is the sealing system. Then, with the use of the CFD model, it was found that the optimum design of the CPC is with the optimized intake port and the short seal. With this configuration, a higher peak pressure is achieved at the end of the compression stroke.

The second feature of the engine examined in this study was the sealing system, where three different labyrinth geometries were considered, namely the one-sided straight, the tooth-interlocking (three variances), and the stepped labyrinth. The stepped design exhibited the best sealing efficiency and it is considered preferable.

Currently, and after concluding with the modeling analysis of the engine, the first prototype of this novel engine is under construction. The initial parts that are being manufactured include the compression chamber and the CPC pistons. Those will constitute the core of the experimental installation that is under development. In parallel, a test campaign is designed for the first experimental assessment of the engine, the results of which will be also used for the validation of the simulation models. 
Supplementary Materials: The following are available online at http://www.mdpi.com/1996-1073/13/9/2362/s1; Video S1: Operating Principle of the SARM engine.

Author Contributions: Conceptualization, S.S. and Y.Y.; methodology, S.S.; software, S.S.; validation, S.S.; formal analysis, S.S.; investigation, S.S.; resources, S.S.; data curation, S.S.; writing-original draft preparation, S.S.; writing-review and editing, E.N., D.M. and Z.S.; visualization, S.S.; supervision, Z.S.; project administration, Z.S.; funding acquisition, Z.S. All authors have read and agreed to the published version of the manuscript.

Funding: This research is co-financed by Greece and the European Union (European Social Fund- ESF) through the Operational Programme "Human Resources Development, Education and Lifelong Learning 2014-2020" in the context of the project "Optimisation of the sealing method for a new concept concentric rotary engine" (MIS 5005530).

Acknowledgments: We would like to thank BETA CAE Systems \& Convergent Science for their free of charge offer of their software (ANSA, META \& CONVERGECFD) and their technical support for the accomplishment of this research. ANSA was used for the geometry creation and pre-processing of the CFD model, CONVERGECFD for the CFD simulations, and META for the post-processing/visualization of the results. Their support was essential and crucial to complete this research.

Conflicts of Interest: The authors declare no conflict of interest. The funders had no role in the design of the study; in the collection, analyses, or interpretation of data; in the writing of the manuscript, or in the decision to publish the results.

\section{References}

1. European Commission. Regulation (EU) 2019/631 of the European Parliament and of the Council of 17 April 2019, Setting $\mathrm{CO}_{2}$ Emission Performance Standards for New Passenger Cars and for New Light Commercial Vehicles, and Repealing REGULATIONS (EC) No 443/2009 and (EU) No 510/2011; European Commission: Brussels, Belgium, 2019.

2. Federal Register, Department of Transportation. 2017 and Later Model Year Light-Duty Vehicle Greenhouse Gas Emissions and Corporate Average Fuel Economy Standards; Final Rule; U.S. Environmental Protection Agency: Washington, DC, USA, 2012; Volume 77, pp. 62623-63200.

3. European Commission. Regulation (EU) 2019/1242 of the European Parliament and of the Council of 20 June 2019, Setting CO2 Emission Performance Standards for New Heavy-Duty Vehicles and Amending Regulations (EC) No 595/2009 and (EU) 2018/956 of the European Parliament and of the Council and Council Directive 96/53/EC; European Commission: Brussels, Belgium, 2019.

4. Statharas, S.; Moysoglou, Y.; Siskos, P.; Zazias, G.; Capros, P. Factors Influencing Electric Vehicle Penetration in the EU by 2030: A Model-Based Policy Assessment. Energies 2019, 12, 2739.

5. Yugo, M.; Soler, A. A Look into the Role of e-Fuels in the Transport System in Europe (2030-2050) (Literature Review). Available online: https://www.concawe.eu/wp-content/uploads/E-fuels-article.pdf (accessed on 1 April 2020).

6. Ash, N.; Sikora, I.; Richelle, B. Electrofuels for Shipping: How Synthetic Fuels from Renewable Electricity Could Unlock Sustainable Investment in Countries Like Chile; Environmental Defense Fund: London, UK, 2019.

7. ERTRAC (European Road Transport Research Advisory Council) Working Group: Energy and Environment. Future Light and Heavy Duty ICE Powertrain Technologies; ERTRAC: Brussels, Belgium, 2016.

8. O'Connor, J.; Borz, M.; Ruth, D.; Han, J.; Paul, C.; Imren, A.; Haworth, D.; Martin, J.; Boehman, A.; Li, J.; et al. Optimization of an Advanced Combustion Strategy Towards 55\% BTE for the Volvo SuperTruck Program. SAE Int. J. Engines 2017, 10, 1217-1227. [CrossRef]

9. Kocher, L. Final Scientific/Technical Report: Enabling Technologies for Heavy-Duty Vehicles-Cummins 55BTE. Available online: https://www.osti.gov/servlets/purl/1474075 (accessed on 1 March 2020). [CrossRef]

10. Castiglione, T.; Morrone, P.; Falbo, L.; Perrone, D.; Bova, S. Application of a Model-Based Controller for Improving Internal Combustion Engines Fuel Economy. Energies 2020, 13, 1148. [CrossRef]

11. Shkolnik, N.; Shknolnik, S. Rotary High Efficiency Hybrid Cycle Engine; SAE Technical Paper 2008-01-2448; SAE International: Warrendale, PA, USA, 2008.

12. Spreitzer, J.; Zahradnik, F.; Geringer, B. Implementation of a Rotary Engine (Wankel Engine) in a CFD Simulation Tool with Special Emphasis on Combustion and Flow Phenomena; SAE Technical Paper 2015-01-0382; SAE International: Warrendale, PA, USA, 2015.

13. Kutlar, O.A.; Malkaz, F. Two-Stroke Wankel Type Rotary Engine: A New Approach for Higher Power Density. Energies 2019, 12, 4096. [CrossRef] 
14. Li, Z.; Shih, T.I.P.; Schock, H.J.; Willis, E.A. A Numerical Study on the Effects of Apex Seal Leakage on Wankel; SAE Technical Papers; SAE International: Warrendale, PA, USA, 1991.

15. Gasim, M.M.; Noor, M.M.; Kadirgama, K. Theoretical Torque Comparison between Revetec Engine and Conventional Internal Combustion Engine. In Proceedings of the 1st National Conference in Mechanical Engineering Research and Postgraduate Students (NCMER 2010), Universiti Malaysia Pahang, Kuantan, Malaysia, 26-27 May 2010.

16. Meldolesi, R.; Badain, N. Scuderi Split Cycle Engine: Air Hybrid Vehicle Powertrain Simulation Study; SAE Technical Paper 2012-01-1013; SAE International: Warrendale, PA, USA, 2012.

17. Ashley, S. New Axial-Piston Engine Aimed at Range Extenders, Military Applications. Available online: https://www.sae.org/news/2014/08/new-axial-piston-engine-aimed-at-range-extenders-militaryapplications (accessed on 1 April 2020).

18. Zima, S.; Ficht, R. Ungewöhnliche Motoren (in German); Vogel Business Media: Würzburg, Germany, 2010.

19. Zhang, Y.; Zuo, Z.; Liu, J. Numerical Analysis on Combustion Characteristic of Leaf Spring Rotary Engine. Energies 2015, 8, 8086. [CrossRef]

20. Savvakis, S.; Gkoutzamanis, V.; Samaras, Z. Description of a Novel Concentric Rotary Engine; SAE Technical Paper 2018-01-0365; SAE International: Warrendale, PA, USA, 2018. [CrossRef]

21. Ferguson, C.R.; Kirkpatrick, A.T. Internal Combustion Engines-Applied Thermosciences; John Wiley \& Sons: Hoboken, NJ, USA, 2001.

22. Blog, T. 8 September 2008. Available online: http://pressroom.toyota.com/article_print.cfm?article_id=2722 (accessed on 1 April 2020).

23. Heywood, J.B. Internal Combustion Engine Fundamentals; McGraw-Hill: New York, NY, USA, 1988.

24. Kobayashi, H.; Sugihara, H.; Yoshida, H.; Kawase, N.; Akimoto, Y. Effect of Top Rings on Piston Slap Noise; SAE Technical Paper 952236; SAE International: Warrendale, PA, USA, 1995. [CrossRef]

25. Gkoutzamanis, V.G.; Savvakis, S.; Kalfas, A.I. Numerical Simulation of a Novel Rotary Engine Compared to Conventional Reciprocating Engine Cycle. In Proceedings of the GPPS Conference 2017, Shanghai, China, 30 October-1 November 2017.

26. Zhang, M.; Yang, J.; Xu, W.; Xia, Y. Leakage and rotordynamic performance of a mixed labyrinth seal compared with that of a staggered labyrinth seal. J. Mech. Sci. Technol. 2017, 31, 2261-2277. [CrossRef]

27. Kang, Y.; Kim, T.S.; Kang, S.Y.; Moon, H.K. Aerodynamic Performance of Stepped Labyrinth Seals for Gas Turbine Applications. In Proceedings of the ASME Turbo Expo 2010: Power for Land, Sea, and Air. Volume 4: Heat Transfer, Parts A and B, Glasgow, UK, 14-18 June 2010; pp. 1191-1199.

28. Memmott, E.A. Empirical Estimation of a Load Related Cross-Coupled Stiffness and the Lateral Stability of Centrifugal Compressors. In Proceedings of the 18th Machinery Dynamics Seminar, Canadian Machinery Vibration Association, Halifax, NS, Canada, 26-28 April 2000.

29. Gao, R.; Kirk, G. CFD Study on Stepped and Drum Balance Labyrinth Seal. Tribol. Trans. 2013, 56, 663-671. [CrossRef]

30. Kim, T.S.; Cha, K.S. Comparative analysis of the influence of labyrinth seal configuration on leakage behavior. J. Mech. Sci. Technol. 2009, 23, 2830-2838. [CrossRef]

31. Eser, D.; Dereli, Y. Comparisons of Rotordynamic Coefficients in Stepped Labyrinth Seals by Using Colebrook-White Friction Factor Model. Meccanica 2007, 42, 177-186. [CrossRef]

32. Stoker, H.L. Determining and Improving Labyrinth Seal Performance in Current and Advanced High Performance Gas Turbines; AGARD-CP-237 (AGARD-AR-123), Paper 13; AGARD: London, UK, August 1978.

33. Waschka, W.; Wittig, S.; Kim, S. Influence of high rotational speeds on the heat transfer and discharge coefficients in labyrinth seals. J. Turbomach. 1992, 114, 462-468. [CrossRef]

34. Ha, T. Rotordynamic Analysis for Stepped-Labyrinth Gas Seals Using Moody's Friction-Factor Model. J. Mech. Sci. Technol. 2001, 15, 1217-1225. [CrossRef]

35. Yuecel, U. Calculation of Leakage and Dynamic Coefficients of Stepped Labyrinth Gas Seals. Appl. Math. Comput. 2004, 152, 521-533. [CrossRef]

36. Subramaniana, S.; Sekhara, A. Rotordynamic characterization of rotating labyrinth gas turbine seals with radial growth_Combined centrifugal and thermal effects. Int. J. Mech. Sci. 2017, 123, 1-19. [CrossRef]

37. Mirzamoghadam, A.V.; Xiao, Z. Flow and heat transfer in an industrial rotor-stator rim sealing cavity. J. Eng. Gas Turbines Power 2002, 124, 125-132. [CrossRef] 
38. Thorat, M.; Childs, D. Predicted rotordynamic behavior of a labyrinth seal as rotor surface velocity approaches mach1. ASME J. Eng. Gas Turbines Power 2010, 132, 112504. [CrossRef]

39. Li, Z.; Li, J.; Feng, Z. Numerical comparisons of rotordynamic characteristics for three types of labyrinth gas seals with inlet preswirl. IMechE Part A J. Power Energy 2016. [CrossRef]

40. Converge Science, Converge CFD 2.4 Manual; CONVERGE CFD: Detroit, MI, USA, 2018.

41. Savvakis, S. Computational Investigation of a Novel Concentric Rotary Engine. Ph.D. Thesis, Aristotle University of Thessaloniki, Thessaloniki, Greece, 2011.

42. Schramm, V.; Denecke, J.; Kim, S.; Wittig, S. Shape Optimization of a Labyrinth Seal Applying the Simulated Annealing Method. Int. J. Rotating Mach. 2004, 10, 365-371. [CrossRef]

(C) 2020 by the authors. Licensee MDPI, Basel, Switzerland. This article is an open access article distributed under the terms and conditions of the Creative Commons Attribution (CC BY) license (http://creativecommons.org/licenses/by/4.0/). 